\title{
Low-Speed Flight Dynamic Tests and Analysis of the Orion Crew Module Drogue Parachute System
}

\author{
David E. Hahne ${ }^{*}$ and C. Michael Fremaux ${ }^{\dagger}$ \\ NASA Langley Research Center, Hampton, VA 23681
}

\begin{abstract}
A test of a dynamically scaled model of the NASA Orion Crew Module (CM) with drogue parachutes was conducted in the NASA-Langley 20-Foot Vertical Spin Tunnel. The primary test objective was to assess the ability of the Orion Crew Module drogue parachute system to adequately stabilize the $\mathrm{CM}$ and reduce angular rates at low subsonic Mach numbers. Two attachment locations were tested: the current design nominal and an alternate. Experimental results indicated that the alternate attachment location showed a somewhat greater tendency to attenuate initial roll rate and reduce roll rate oscillations than the nominal location. Comparison of the experimental data to a Program To Optimize Simulated Trajectories (POST II) simulation of the experiment yielded results for the nominal attachment point that indicate differences between the low-speed pitch and yaw damping derivatives in the aerodynamic database and the physical model. Comparisons for the alternate attachment location indicate that riser twist plays a significant role in determining roll rate attenuation characteristics. Reevaluating the impact of the alternate attachment points using a simulation modified to account for these results showed significantly reduced roll rate attenuation tendencies when compared to the original simulation. Based on this modified simulation the alternate attachment point does not appear to offer a significant increase in allowable roll rate over the nominal configuration.
\end{abstract}

\section{Nomenclature}

$\mathrm{C}_{\mathrm{A}} \quad=$ axial force coefficient

$\mathrm{C}_{\mathrm{D}} \quad=$ drag coefficient

$\mathrm{C}_{\mathrm{N}} \quad=$ normal force coefficient

$\mathrm{C}_{\mathrm{Y}} \quad=$ side force coefficient

$\mathrm{C}_{1} \quad=$ rolling moment coefficient

$\mathrm{C}_{\mathrm{m}} \quad=$ pitching moment coefficient

$\mathrm{C}_{\mathrm{n}} \quad=$ yawing moment coefficient

$\ell=$ length, ft or in.

$\mathrm{M}_{\infty} \quad=$ free stream Mach number

$\mathrm{N}=$ model-to-vehicle scale factor, $\ell_{\mathrm{m}} / \ell_{\mathrm{fs}}$

$\overline{\mathrm{q}}=$ free stream dynamic pressure, $\mathrm{lb} / \mathrm{ft}^{2}$

$\operatorname{Re}_{\infty} \quad=$ free stream Reynolds number per foot

$\mathrm{S} \quad=$ laid-out-flat area of flat circular parachute, $\mathrm{ft}^{2}$

$\mathrm{u}, \mathrm{v}, \mathrm{w}=$ components of free-stream velocity in the $\mathrm{x}, \mathrm{y}$, and $\mathrm{z}$ directions, respectively, $\mathrm{ft} / \mathrm{s}$

$\mathrm{V}=$ velocity, $\mathrm{ft} / \mathrm{s}$

$\mathrm{x}, \mathrm{y}, \mathrm{Z}=$ tunnel-fixed axes with $\mathrm{x}$ pointing down in test section

$\mathrm{X}, \mathrm{Y}, \mathrm{Z}=$ distance along the $\mathrm{x}, \mathrm{y}$, or $\mathrm{z}$ axes in tunnel-fixed axis system, $\mathrm{ft}$ or in

$\alpha \quad=$ angle of attack, $\operatorname{deg}\left(\alpha=0^{\circ} \Rightarrow\right.$ tower apex forward/down in VST)

$\alpha_{\mathrm{T}} \quad=$ total angle of attack, deg

$\beta \quad=$ angle of sideslip, deg

$v \quad=$ kinematic viscosity, $\mathrm{ft} / \mathrm{s}^{2}$

$\rho \quad=$ air density, slugs $/ \mathrm{ft}^{3}$

\footnotetext{
* Sr. Research Engineer, Atmospheric Flight \& Entry Systems Branch, MS/489

${ }^{\dagger}$ Branch Head, Flight Dynamics Branch, MS/308, Senior Member
} 


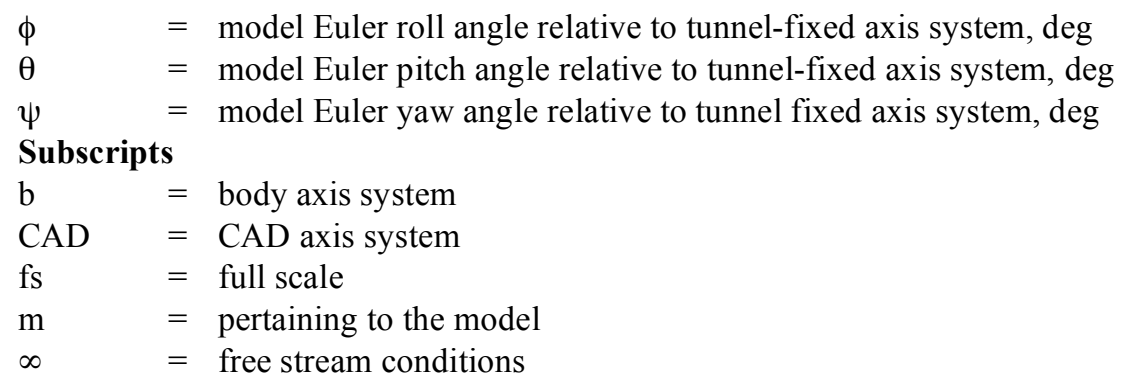

\section{Introduction}

N experimental and analytical investigation of the low-speed flight dynamics of the NASA Orion Crew Explo-

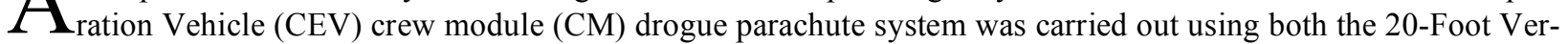
tical Spin Tunnel (VST) and numerical simulations at NASA Langley Research Center (LaRC). For the experimental part of the work in the VST, a 1/29-scale model of the CM was dynamically scaled (weight, center of gravity, and moments of inertia) to represent the full-scale vehicle operating at an altitude of $25000 \mathrm{ft}$. These conditions represent a nominal atmospheric re-entry or high-altitude launch abort. Both single-point (baseline) and multi-point (alternate) parachute towline attachment points were tested. During each test run, an initial rotation rate was imparted to the model just prior to parachute deployment in order to assess the ability of the system to damp out angular rates, particularly body-axis roll rate. Attitude and position motion time histories for each run, as well as documentation video, were the primary data products of the test entry. An existing Program To Optimize Simulated Trajectories (POST II) simulation of the CM was modified to replicate the conditions of the VST test. Experimental motion time histories, post-processed to convert the raw test results to full-scale body-axis rates, were compared to the output of the simulation in order to identify needed adjustments in the simulation parameters. These adjustments were then implemented in the original simulation to assess the predicted fullscale dynamic behavior of the $\mathrm{CM} /$ parachute system. The experimental and analytical results indicate that the both of the drogue parachute configurations tested will adequately damp out angular rates about all three axes as long as the roll rate at deployment is below a certain threshold.

The primary objective of the experimental and analytical studies was to assess the ability of the Orion Crew Module drogue parachute system to adequately stabilize the CM and reduce angular rates prior to main parachute deployment. The secondary objective was to benchmark a simulation of the $\mathrm{CM}$ and drogue parachute system and make adjustments to the simulation parameters if necessary.

\section{Facility and Model}

The wind tunnel tests were performed in the Langley 20-Foot Vertical Spin Tunnel. The VST is an atmospheric, lowspeed, annular return tunnel with a closed, twelve-sided test section that is 20 feet wide and 25 feet long. The maximum tunnel dynamic pressure $(\overline{\mathrm{q}})$ is approximately

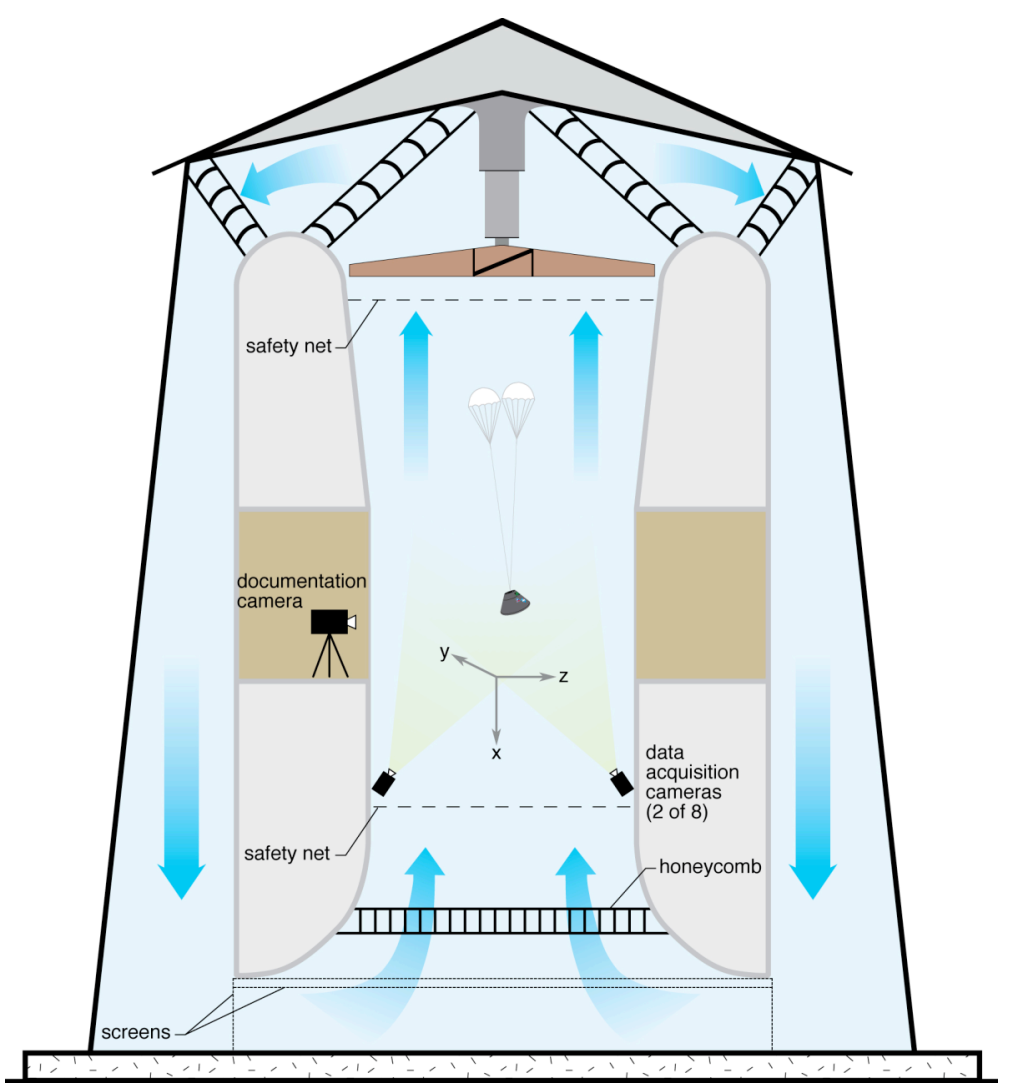

Figure 1. Schematic of NASA Langley 20-Foot Vertical Spin Tunnel showing tunnel-fixed axis system. 
$9 \mathrm{lb} / \mathrm{ft}^{2}$ at a speed of $87 \mathrm{ft} / \mathrm{s}\left(\mathrm{Re}_{\infty}=550,000\right.$ per foot $)$. The fan drive control is designed to provide rapid acceleration and deceleration of the flow $\left(+15 \mathrm{ft} / \mathrm{s}^{2}\right.$ and $-25 \mathrm{ft} / \mathrm{s}^{2}$, respectively) through a joystick controller so that a model may be kept (vertically) in the designated test volume. A light weight "safety tether" system can be used to minimize model damage and reduce test time when appropriate, but it was not used for this test due to a tendency of the model parachute risers to foul with the tether. A cross sectional sketch of the facility is shown in Figure 1.

The 1/29-scale models were built at the LaRC rapid prototyping lab using an automated polycarbonate fabrication system. Design of the model was based on the vehicle outer mold line (OML) Pro/E CAD files. A photograph of the completed model is shown in Figure 2. Note that the parachute system hardware (packed main parachutes, drogue parachute canisters, etc.) that occupies the space between gussets was not modeled between the gussets for this test nor were any other protuberances. The finished model was painted flat black in order to minimize reflected light that could have caused interference with an optical data acquisition system (NASA and Project Orion emblems were affixed to the sides of the models with no deleterious effect).

Deployment of the model parachutes during test runs was accomplished using ejector springs installed under the packed parachutes. Off-the-shelf radio control $(\mathrm{R} / \mathrm{C})$ equipment was used to remotely trigger the ejectors by pulling a lanyard and pin arrangement with a servo/receiver/battery combination installed in the model. Lead weights were added to the model in order to simulate the mass properties (weight, center of gravity, and moments of inertia) of the vehicle operating at an altitude of $25,000 \mathrm{ft}$ according to the principles of Froude scaling (discussed below).

The model parachutes used for these tests were obtained from the inventory kept on hand at the VST for airplane spin-recovery and entry vehicle drogue parachute testing. The nominal 9.5-inch diameter flat, circular parachutes are constructed of high permeability nylon for good stability, and have drag coefficients, $\mathrm{C}_{\mathrm{D}}$, of approximately 0.52 . The equivalent full-scale drag area, $\mathrm{C}_{\mathrm{D}} \mathrm{S}$, of each parachute was $215 \mathrm{ft}^{2}$ (nearly identical to the actual drogue parachutes currently being tested). Drag coefficient and diameter were the only physical characteristic of the proposed CEV drogue parachutes that were modeled in these tests. The towline length of each parachute (i.e., riser plus suspension line length) was 41 inches model scale (99 feet full-scale) for the majority of the tests, and 123 feet for the remainder of the tests as indicated in the results section. Two parachutes were used for every test run. A photograph of the parachutes appears in Figure 3.

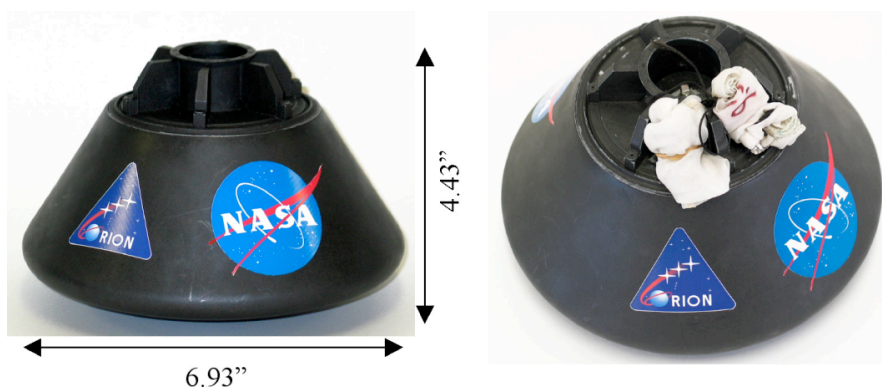

Figure 2. Basic 1/29-scale Orion CM model (left), and with packed model parachutes installed (right) for drogue parachute tests in 20-Foot Vertical Spin Tunnel.

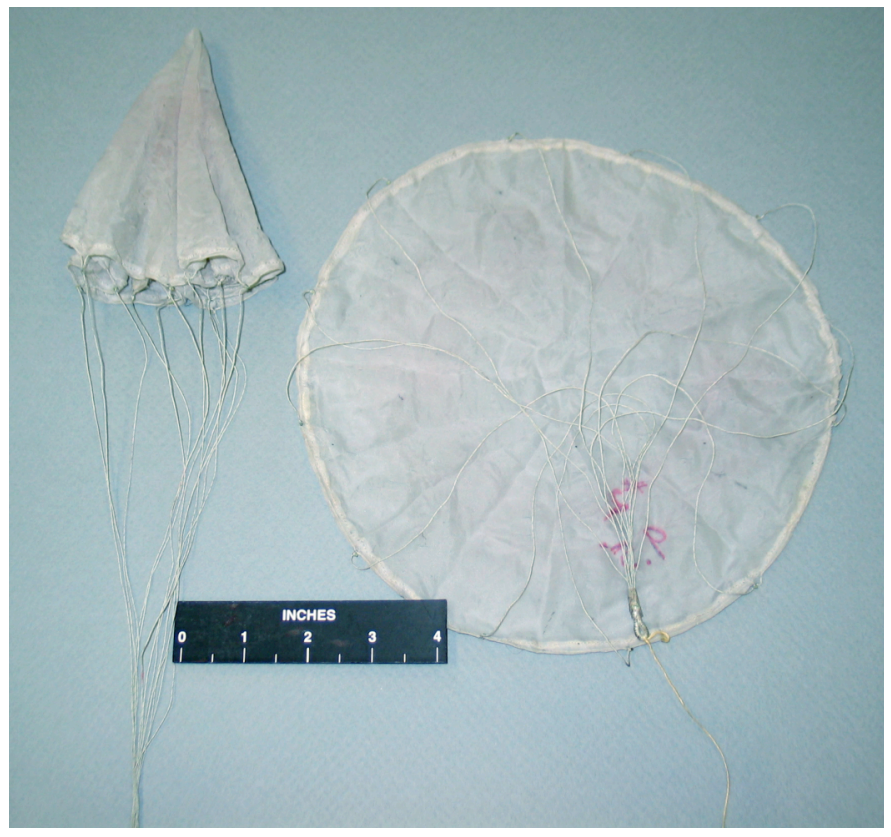

Figure 3. 9.5-inch flat circular parachutes used in drogue parachute tests in 20-Foot Vertical Spin Tunnel.

The parachute towlines were attached to the model in two different configurations during the test to assess the effect of attachment point location on the ability of the drogues to stabilize the vehicle. The nominal configuration had the two towlines attached to a single attachment point located on the 0-degree gusset inboard near the tunnel flange. Figure 4 shows the packed parachutes attached to the nominal attachment point (note black towline tied to the inner 0-degree gusset). The alternate attachment point had each parachute attached at a different location (the 60degree and 300-degree gussets). 


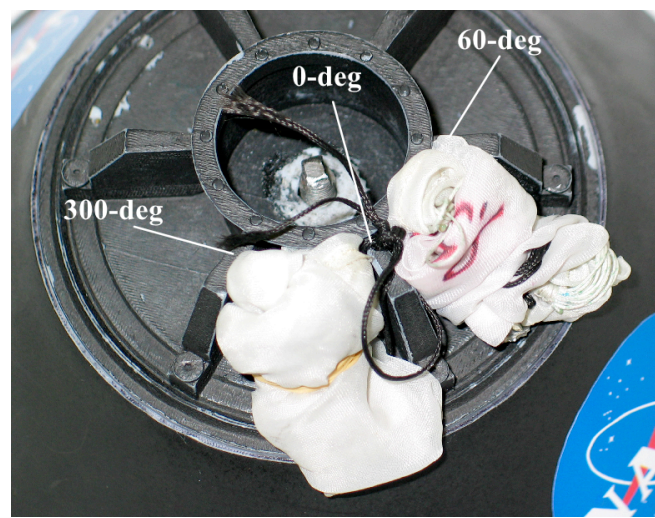

Figure 4. Nominal and alternate towline attachment points on $1 / 20$-scale $\mathrm{CM}$ model.

Table 1. Dynamic scaling factors based on equal Froude number and relative density

\begin{tabular}{lc}
\hline \hline \multicolumn{1}{c}{ Parameter } & Scale Factor \\
\hline Linear Dimension & $\mathrm{N}=\ell_{\mathrm{m}} / \ell_{\mathrm{fs}}$ \\
Relative Density & 1 \\
Froude Number & 1 \\
Mass & $\mathrm{N}^{3} \rho_{\mathrm{m}} / \rho_{\mathrm{fs}}$ \\
Moment of Inertia & $\mathrm{N}^{5} \rho_{\mathrm{m}} / \rho_{\mathrm{fs}}$ \\
Linear Velocity & $\mathrm{N}^{1 / 2}$ \\
Linear Acceleration & 1 \\
Angular Velocity & $1 / \mathrm{N}^{1 / 2}$ \\
Time & $\mathrm{N}^{1 / 2}$ \\
Reynolds Number & $\mathrm{N}^{3 / 2} v_{\mathrm{m}} / v_{\mathrm{fs}}$ \\
\hline \hline
\end{tabular}

The required model mass properties were calculated based on the principle of Froude scaling (i.e., similitude by equating the ratio of model inertial forces to gravitational force of the model to that of the full-scale vehicle) and by equal relative density (i.e., the ratio of model density to that of air at the test altitude is equal to that of the vehicle at its flight altitude assuming the 1976 U.S. Standard Atmosphere in Reference 1). A detailed discussion of dynamic scaling can be found in Reference 2 and all the scaling parameters used for this study are presented in Table $1(\mathrm{~N}=0.0345)$. The coordinate system used for all reduced data is presented in Figure 5.



Figure 5. Coordinate system for the Orion Crew Module. All quantities measured relative to body axis system $\left(X_{b}, Y_{b}, Z_{b}\right)$.

\section{Data Acquisition}

The test model was not equipped with any active onboard instrumentation. Rather, an optical data acquisition system was used to passively image a series of small retro-reflective targets on the model in order to reconstruct the six degree-of-freedom (6-DOF) motion and attitude time histories during a test run. The output of the system is the $(\mathrm{X}, \mathrm{Y}, \mathrm{Z}$ ) position of the model reference center (nominal center-ofgravity location) and Euler angles $(\phi, \theta, \psi)$ relative to the tunnel axis system (Figure 1) that is located approximately at the center of the test section. The Euler rotation order is "1-2-3", or "X-Y-Z". The data acquisition system (DAS) is a customized version of the Vicon MX Nexus ${ }^{\mathrm{TM}}$ photogrammetry system that was developed for the biomedical and digital animation fields, and was installed in the VST in the Fall of 2006. The VST Nexus system uses a series of eight digital cameras to image a pattern of retro-reflective targets on the bottom surface (heat shield) of the model at a sample rate of $150 \mathrm{~Hz}$ using near-infrared light emitting diodes (LED) as a light source. A photograph of the target pattern used on the heat shield of the model is shown in Figure 6.

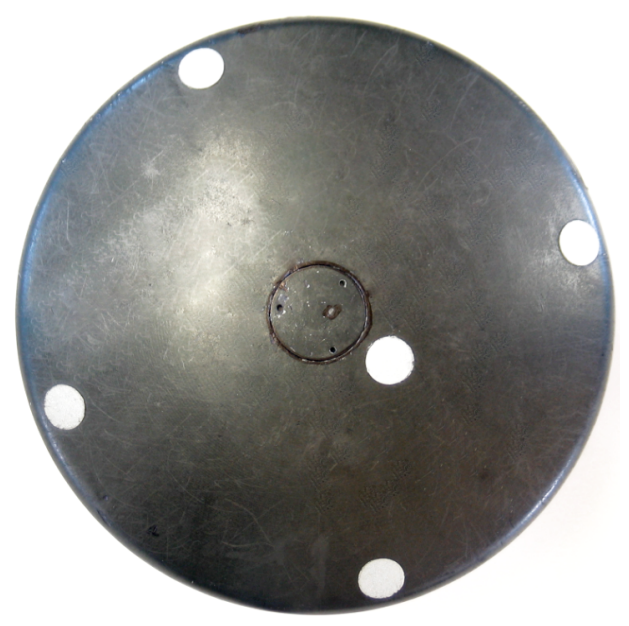

Figure 6. Retro-reflective targets affixed to model heat shield for tracking with optical data acquisition system. 
Each camera is equipped with an onboard processor that calculates the coordinates of the imaged targets in near real time and then sends these coordinates (as opposed to video frames) to the host computer for processing. A minimum of two views of each target is required to perform the photogrammetric resection and reconstruct the 6-DOF time history; eight cameras are used to strengthen the solution and to provide better coverage of the test section. Analog tunnel state information (dynamic pressure, etc.) is simultaneously sampled at the same frame rate of the cameras and recorded.

\section{Test Procedure}

The Reynolds number varied during the tests due to changing dynamic pressure, but was on the order of 225,000 (based on model maximum diameter) prior to parachute deployment, and 175,000 during equilibrium descent with the parachutes fully inflated. The Mach number, $\mathrm{M}_{\infty}$, was approximately 0.05 at parachute deployment.

At the start of each run, the photogrammetric system and documentation video camera were activated with the model held in the open test section launch door by a technician to verify that the system was tracking the targets properly. After being given a verbal signal by the test engineer, the technician released the model while simultaneously imparting either a positive or negative roll rate. With some practice, the test team was able to roughly approximate the required roll rate "bins" in the test matrix. A range of roll rates from $20 \mathrm{deg} / \mathrm{s}$ to $100 \mathrm{deg} / \mathrm{s}$ (in $20 \mathrm{deg} / \mathrm{s}$ increments) was tested. Note that the roll rate magnitude values are targets only, and were approximated with the hand-launch technique described above. Both positive and negative roll rates were obtained for each run in order to account for any model asymmetries that may have been caused by damage as the test progressed.

Since it was desired to deploy the parachutes with the model free-flying, a strategy was needed to allow the fan sufficient time to spool down at parachute deployment to avoid the model being drawn into the upper safety net due to the rapid increase in drag. With some trial and error, a strategy was devised in which the test section dynamic pressure was set to a level that was about $60 \%$ of that required for the model to fly in equilibrium (i.e., vertical sink rate matched by test section velocity), the model was launched, and the signal to deploy the parachutes was immediately sent to the model. Ideally, the parachutes deployed low in the test section but remained in the field of view of the photogrammetric cameras. As the parachutes started to deploy, the test engineer immediately began reducing tunnel dynamic pressure to a level that brought the model with parachutes inflated to an equilibrium sink rate until data acquisition was complete. This process was repeated until all of the desired runs in the test matrix were obtained. A time-lapse photograph of the launch sequence appears in Figure 7.

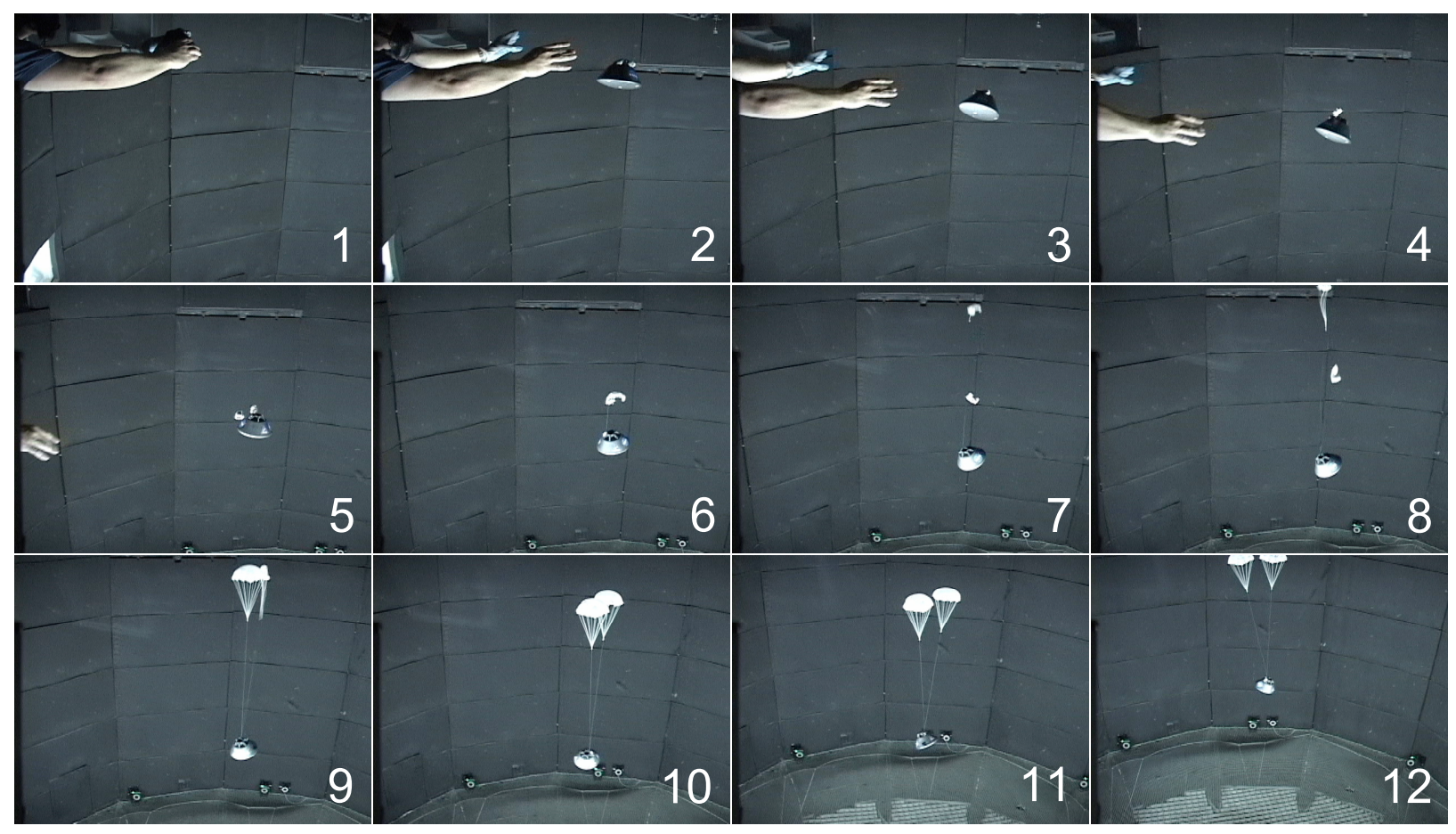

Figure 7. CM model with drogue parachutes being tested in the VST.

American Institute of Aeronautics and Astronautics 092407 


\section{Simulation Methodology}

Both pre- and post-test simulations were conducted using the Program to Optimize Simulated Trajectories II (POST II). POST II has been used extensively in support of planetary entry, descent, and landing analyses for numerous missions. The simulations utilized the multibody capability developed for POST II that is documented in reference 3. The simulation uses a 6 degree-of-freedom (6-DOF) model for the capsule and models the parachutes as drag-only 3-DOF bodies. The simulation uses aerodynamic coefficients derived from the Apollo aerodynamic database to model of the capsule characteristics. Some simulation cases used the final Apollo aerodynamic database to facilitate sensitivity studies of certain aerodynamic coefficients.

The first simulation was developed prior to the wind tunnel test to assess the potential impact of alternate drogue attachment points and to aid in developing a test plan. This was a simulation of the full-scale nominal descent beginning just prior to drogue deployment and ending at drogue release. The atmospheric model used for this simulation was the 1976 US Standard Atmosphere (Reference 1). The projected full-scale CEV mass properties were used and initial conditions were taken from an existing nominal descent profile. Other than the drogue attachment point, only the initial body axis roll rate was purposely varied in this simulation. The drogue deployment and inflation sequence as projected by CPAS as of February 2007 was used as the baseline and included both the projected reefing ratios and disreef timings. A mortar exit velocity of $125 \mathrm{ft} / \mathrm{sec}$ was assumed in modeling the mortars and the parachute inflation model described in reference 4 was used to model the initial inflation and the disreef inflation.

The second simulation was developed to duplicate the conditions and configurations of the Spin Tunnel tests. Model mass properties were scaled up to full-scale values using Froude scaling for an altitude of 25,000 feet. To match the test environment, atmospheric density was held constant. The drogue parachute attachment points were adjusted to match the as-tested model and the mortar velocity and inflation models were adjusted to match the representative timelines extracted from test video. The initial conditions for the simulation were taken directly from the time history data obtained in the test. The drogue full-open time was determined from the measured vertical acceleration and the simulation drogue deployment time was then adjusted accordingly using the representative timeline.

\section{Results}

Sample tunnel data (with all quantities converted to full-scale using the dynamic scaling parameters presented in Table 1) from these tests are shown in Figures 8 and 9. In Figure 8, the change in model position (nominal center-ofgravity position) with time from model release is plotted. Note that the $+\mathrm{X}$ direction in the VST axis system points downward (Figure 1), so that the model dropping in the test section just after launch results in $\mathrm{X}$ becoming more positive. Likewise, as the parachutes are deployed, the sink rate is arrested and then reversed (i.e., $\mathrm{X}$ decreases and becomes more negative). Similarly, the attitude of the model (Euler angles $\psi, \theta$, and $\phi$ labeled as yaw, pitch, and roll, respectively) after launch is plotted in Figure 9. Note that the initial excursions in pitch and yaw amplitude are damped toward limit cycle behavior by the deployment of the drogues. The roll rate imparted to the model at launch is evident in the initial slope of the roll curve (in this case approximately $+35 \mathrm{deg} / \mathrm{s}$ full-scale).

Direct comparisons of the experimental data between the nominal and alternated attachment points are presented in figures 10 and 11. Figure 10 illustrates the tendency of the alternate attachment point configuration to attenuate the initial roll rate to a greater extent. A tendency for positive roll rates to damp out sooner can also be seen. This is attributed to slight asymmetries in the model. A comparison between the nominal and alternate at-

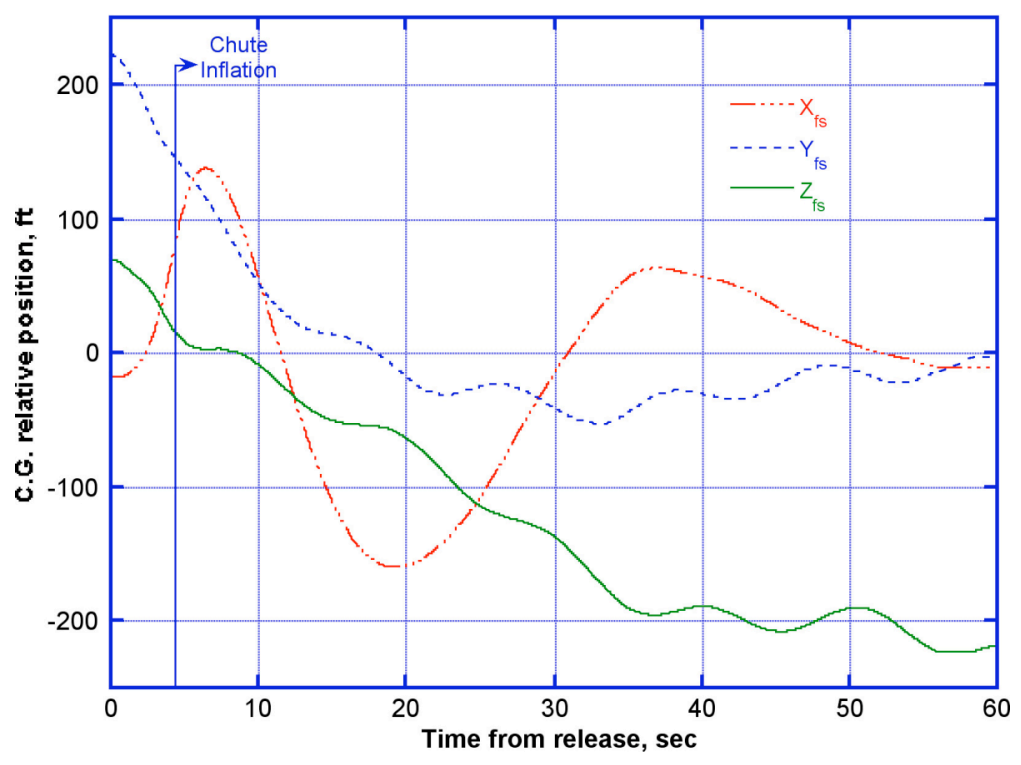

Figure 8. Position time history of CM model relative to VST coordinate system using nominal attachment point for drogue chutes. Values are full-scale converted from model-scale. 
tachment locations, Figure 11, shows that yaw rates were greatly reduced for the alternate attachment point. Pitch rate response did not seem to be affected by attachment location.

Figure 12 shows the comparison of experimental body axis rates with those from the POST II simulation of the experiment for the nominal attachment point. As can be seen the simulation does not predict the same level of roll rate attenuation as exhibited by the experimental data. Also, the amplitude of the rate oscillations in all three axes is significantly higher for the simulation when compared to the experiment. This indicates that the pitch, roll, and yaw damping derivatives in the capsule aerodynamic database are lower (less damped) than those experienced during the test. However, the frequency of the pitch and yaw rate oscillations do match quite well between the experiment and simulation. This indicates that the static pitching and yawing moment coefficients in the capsule aerodynamic database are in good agreement with the model characteristics.

Assuming the database static stability values in pitch and yaw are correct, an examination was made to assess the impact of variations in pitch and yaw damping. Because of the manner in which the Project Orion aerodynamic database has been implemented across the project, it was necessary to use an existing Apollo database for the static aerodynamic coefficients and simple mono-variant (function of angle of attack only) tables for pitch and yaw damping (unlike the Orion database which is a function of Mach, angle of attack, and angle of sideslip). For this evaluation of variations in damping, data for $\mathrm{M}_{\infty}=0.3$ and zero sideslip angle were used to create data tables for pitch and yaw damping in POST II that varied only with angle of attack. The primary drawback to this is that the damping derivatives in the Orion database are a function not only of Mach number and angle of attack but also of sideslip angle. As the amplitude of the rate oscillations was significantly higher in the simulation, peaks in unstable damping near the average angle-of-attack $\left(\sim 155^{\circ}\right)$

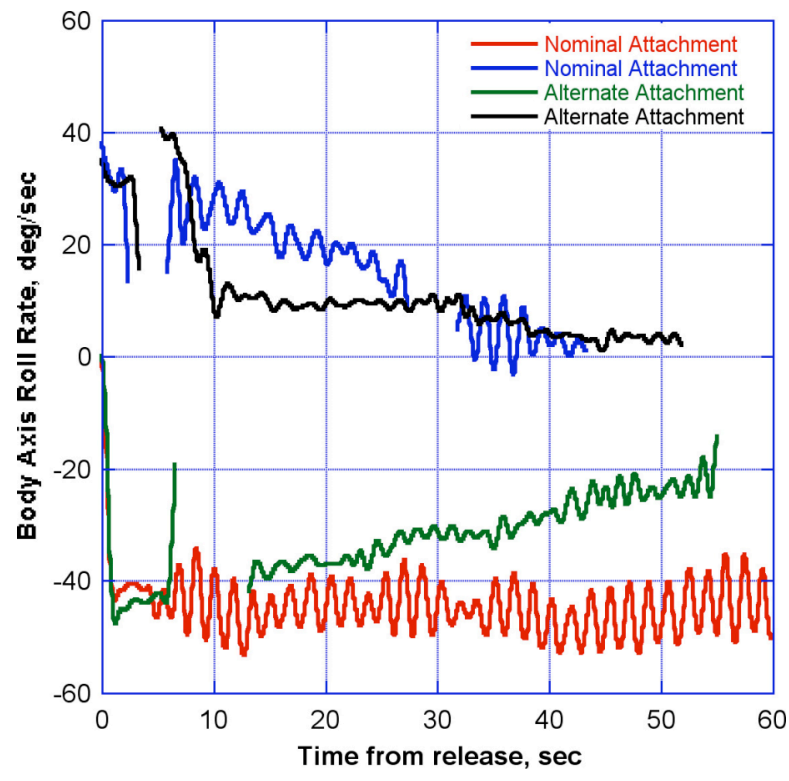

Figure 10. Effect of attachment point on roll rate. Initial roll rate $\pm 40 \mathrm{deg} / \mathrm{sec}$. were examined and modified. For pitch damping, the magnitude of the unstable damping peak at $\alpha=160^{\circ}$ was reduced by a factor of four with no other changes being made (Figure 13, left). Comparison of the baseline values of yaw damping to low-speed data obtained for Apollo (reference 5) indicated a total reversal in the stability of the yaw damping near the average angle-of-attack $\left(\sim 155^{\circ}\right)$. The curve was smoothed somewhat and the level of stable damping reduced slightly for use in the modified damping tables. The final yaw damping characteristics are shown in the right half of Figure 13. It should be noted that there is little beyond engineering judgment that went into the modified values of pitch and yaw damping. 

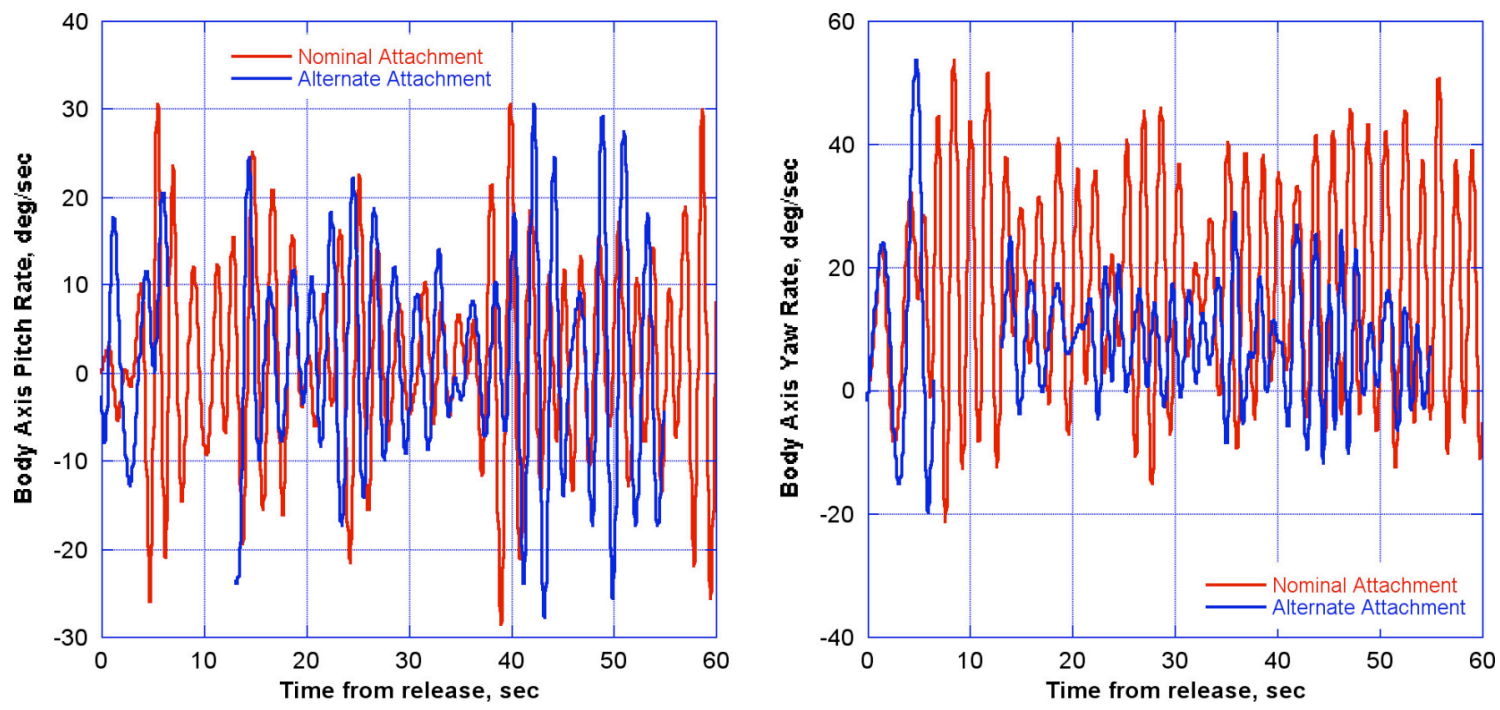

Figure 11. Effect of attachment point on pitch and yaw rate. $-40 \mathrm{deg} / \mathrm{sec}$ initial roll rate.

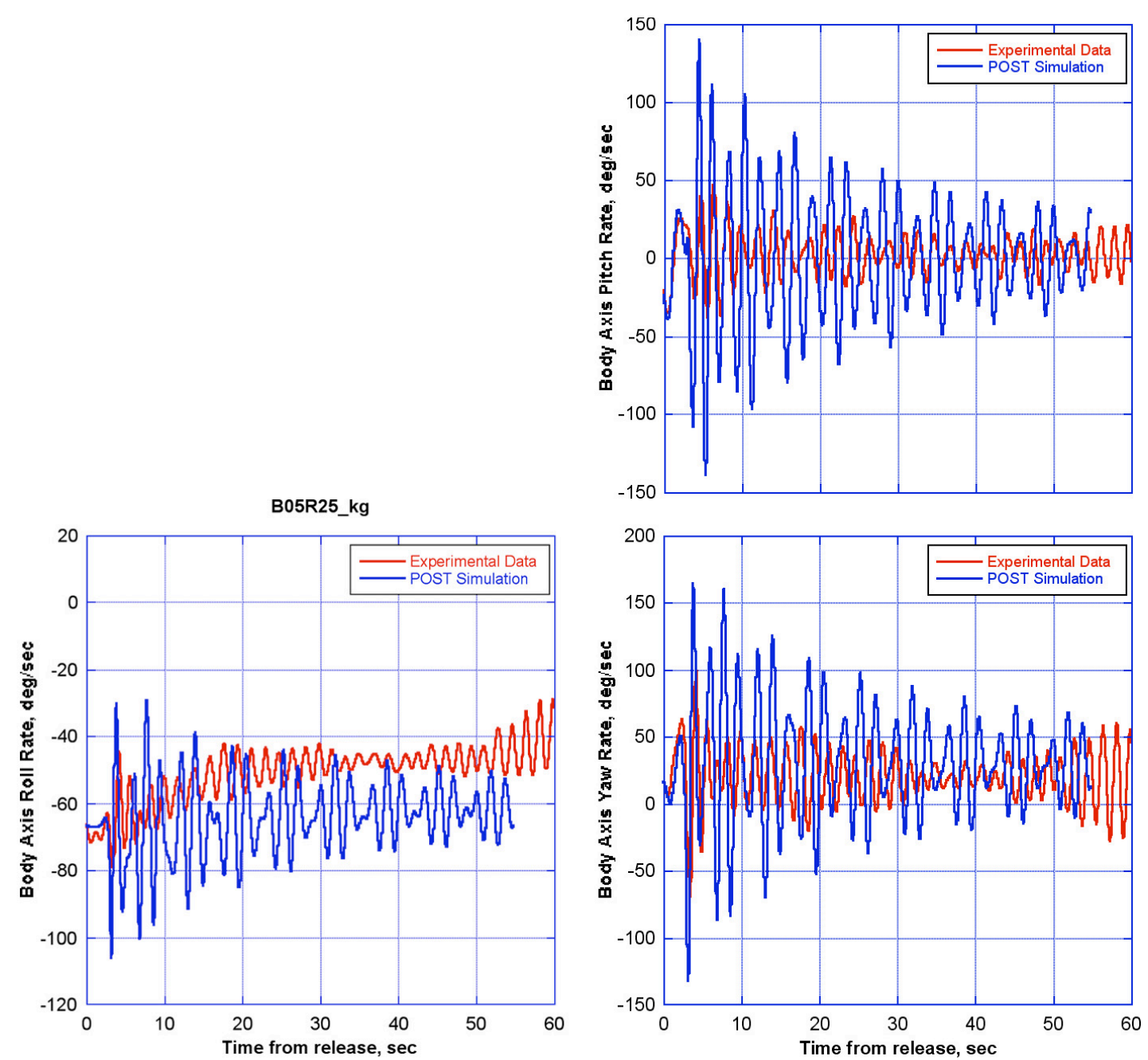

Figure 12. Comparison of experimental data and simulation results. Nominal attachment point. 

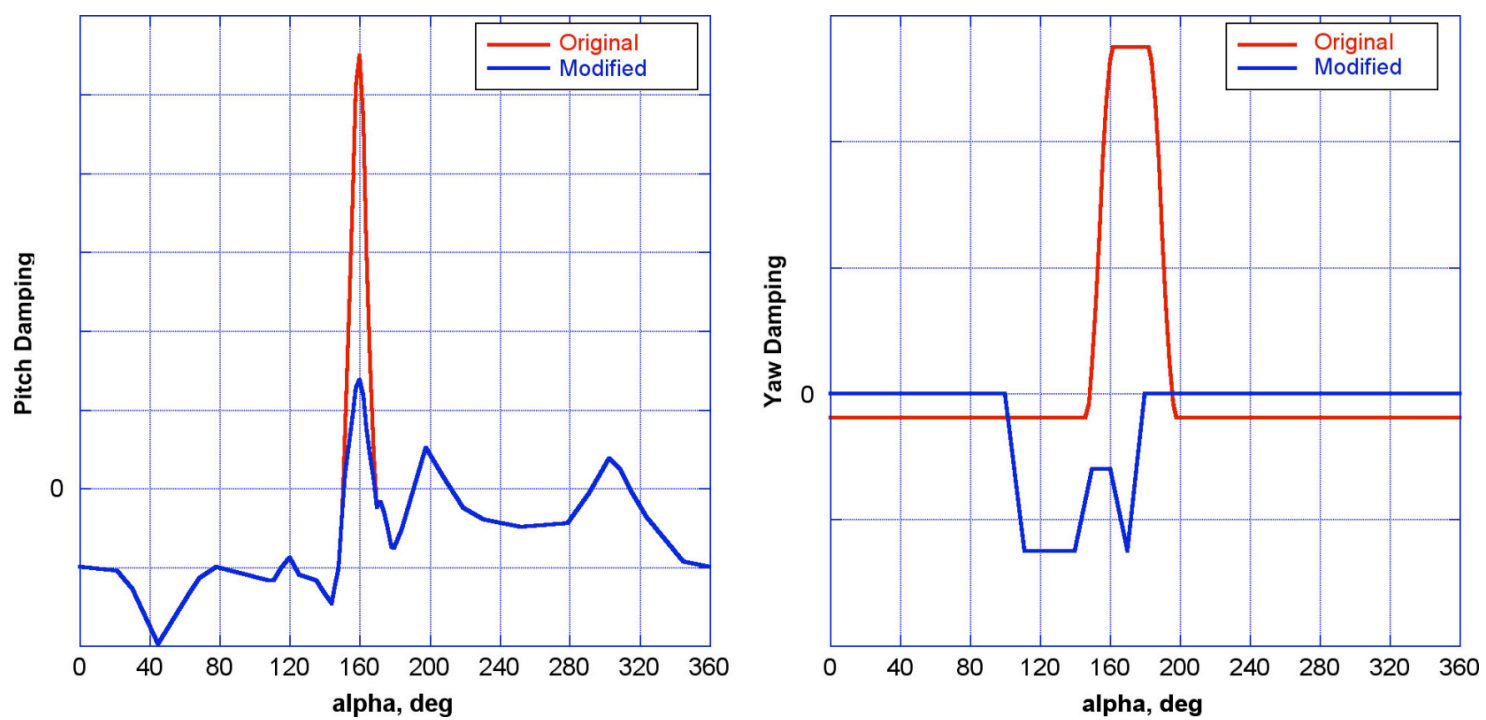

Figure 13. Modifications to pitch and yaw damping.
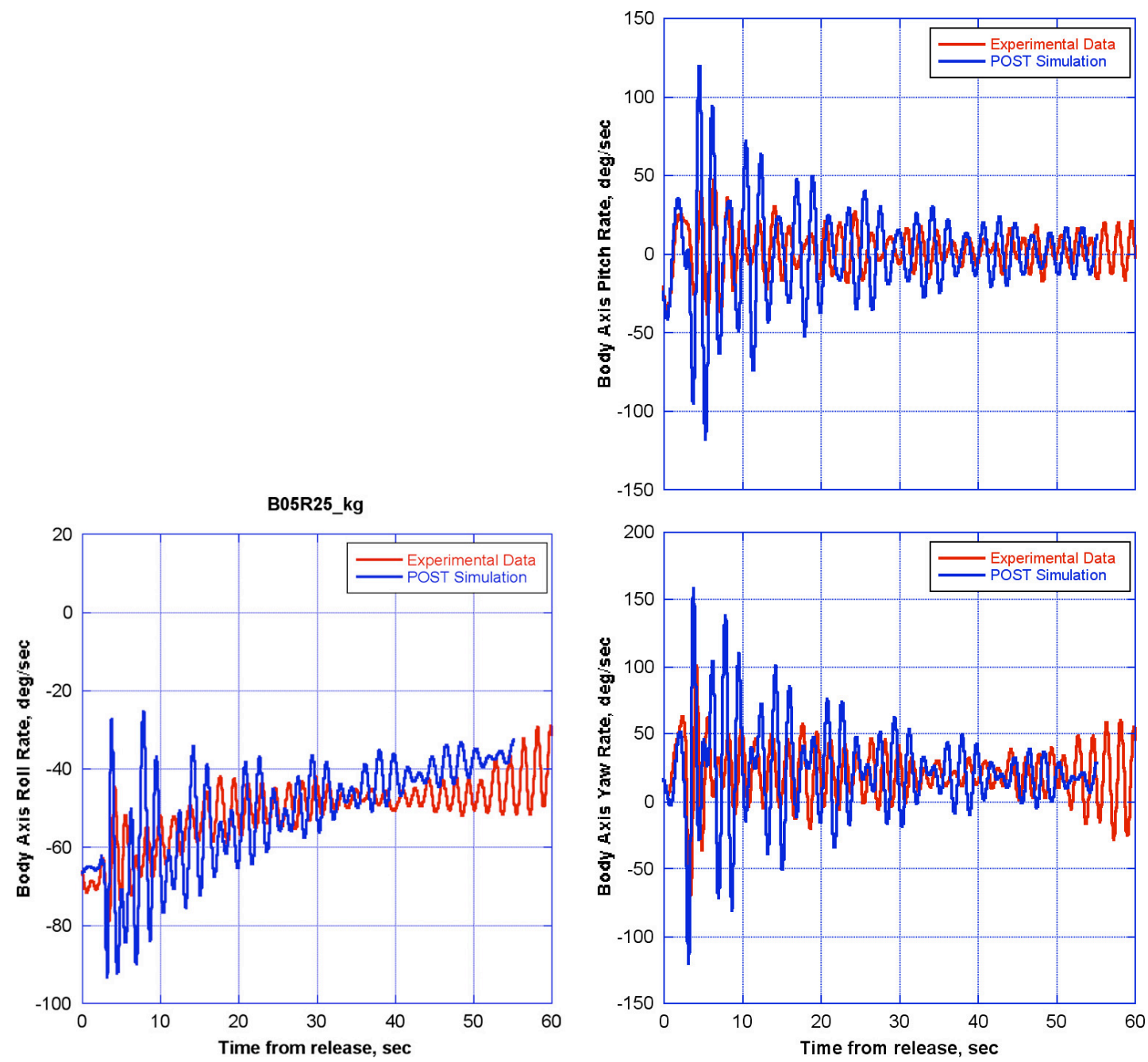

Figure 14. Effect of modified damping simulation results. Nominal attachment point.

American Institute of Aeronautics and Astronautics 
Figure 14 shows the results these modifications on damping had on the simulation results. Most notable is that the amplitude of the rate oscillations is much closer to the experimental data for all axes. Even the general rise and fall characteristics in oscillation amplitude are beginning to be displayed by the simulation. The general decay of roll rate over time is also more in line with the experimental data. Figure 15 illustrates that this improvement in the prediction of roll rate attenuation is due largely to the modification of the yaw damping characteristics.

Using the modified damping coefficients derived for the nominal attachment configuration, a simulation of the alternate attachment points was then made and compared to the experimental data (Figure 16). In this case the dynamic behavior of the simulation, particularly for roll rate, was completely different from the experiment. The simulation still showed the drastic reduction in roll rate seen in the pre-test predictions (one of the reasons for pursuing an evaluation of the alternate attachment points) that was not evident in the

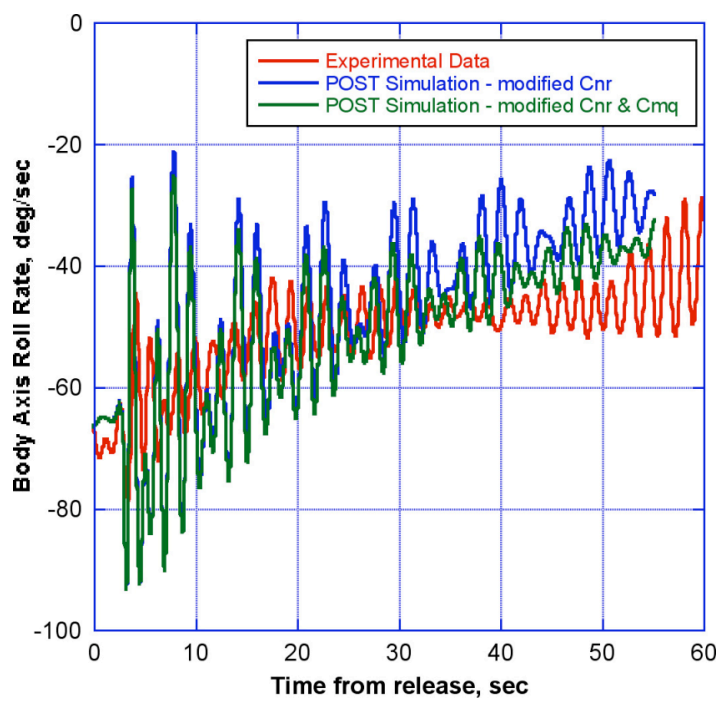

Figure 15. Impact of yaw damping modification on simulation results. Nominal attachment point.
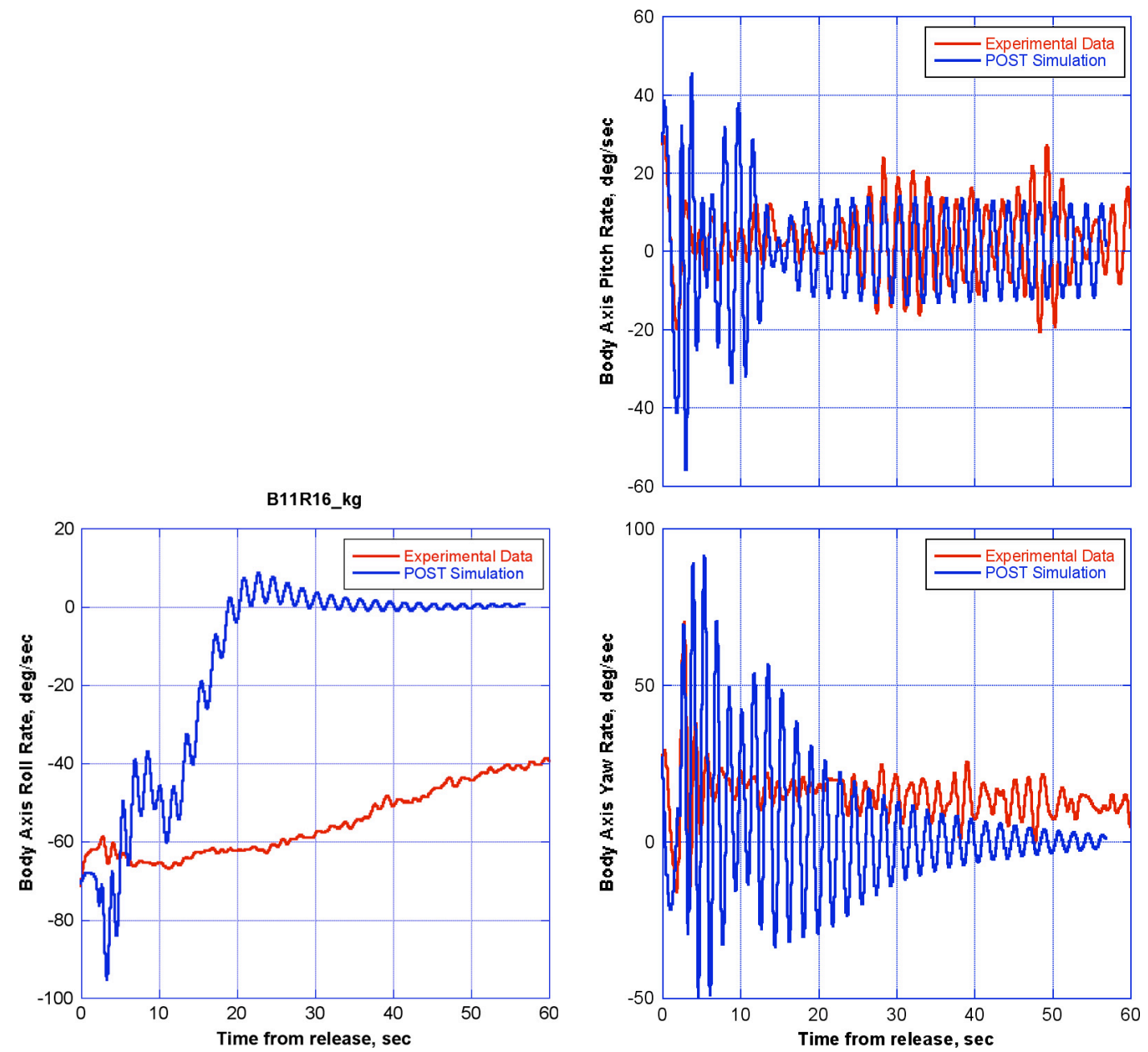

Figure 16. Comparison of experimental data to simulation results. Alternate attachment points and modified damping. 
experimental data. Significant differences in pitch and yaw rate oscillations also existed.

During the experimental testing it had been noticed that the parachute risers would twist together as the capsule was spinning. POST II does not have the ability to model the interaction of the risers as they cross and twist. The risers are simply modeled as a line of force between the capsule and the parachutes. This limitation is not critical for the nominal attachment (a single point attachment) but does become important for the alternate two-point attachment configuration. For the alternate configuration this twisting of the risers creates a situation where effectively the system behaves as if there are two bridles connected from separate attachments on the capsule to a confluence fitting with the parachute risers then connected to this fitting. This was modeled in the POST II simulation by placing a near mass-less node at the approximate location of the riser twist as illustrated in Figure 17. This of course is only a rough approximation of the physics involved as initially in the experiment the risers are not twisted and can actually slip some before too many twists occur while the simulation models this as a fixed node that exists from the very beginning of the parachute deployment sequence.

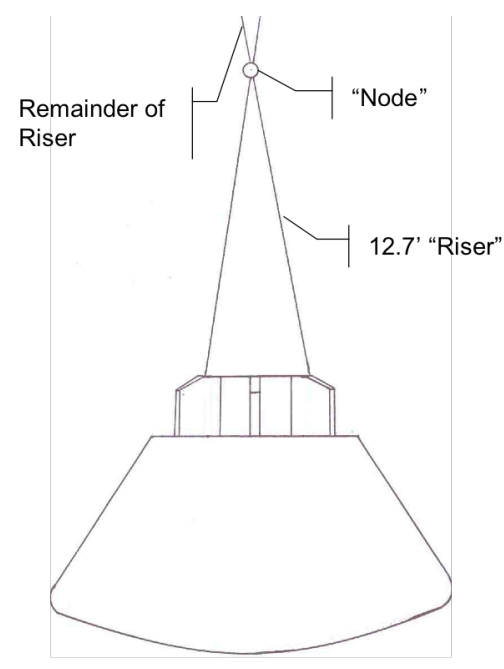

Figure 17. "Model" used to approximate riser twist.
B11R16_kg

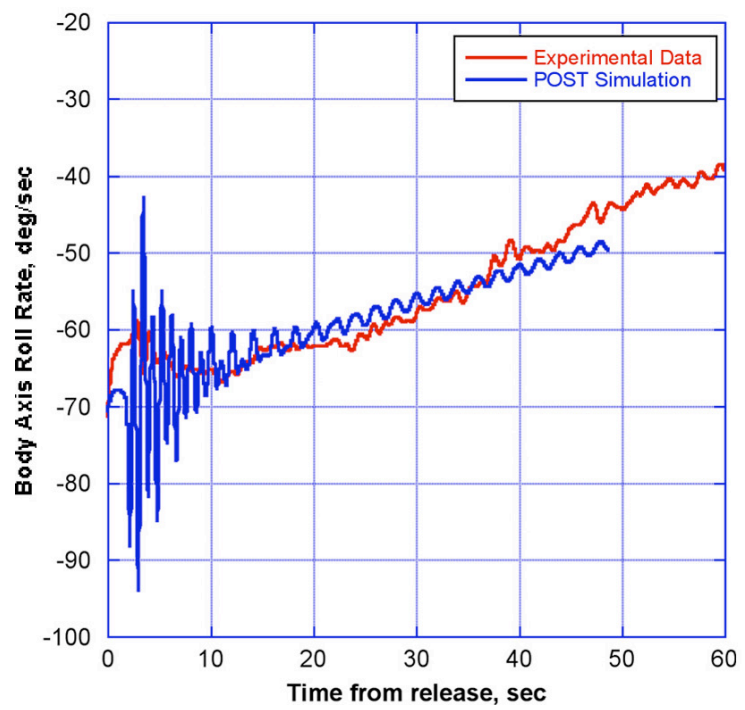

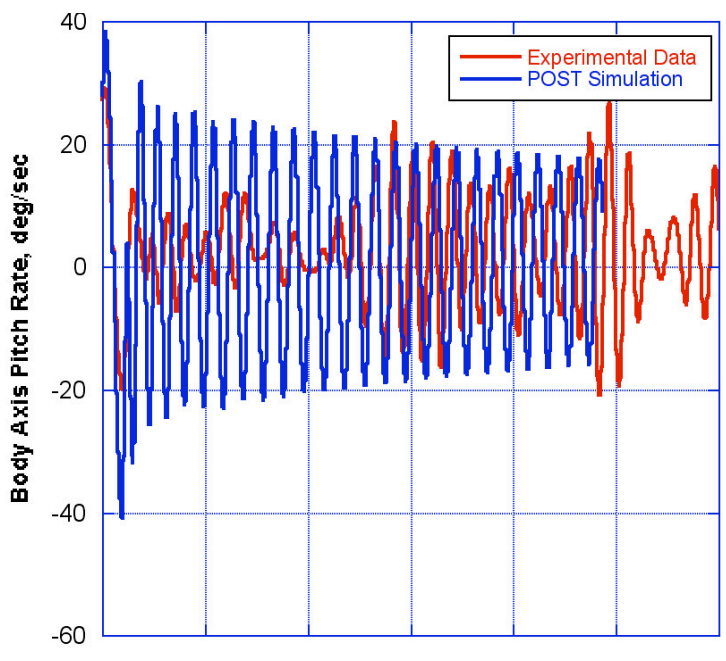

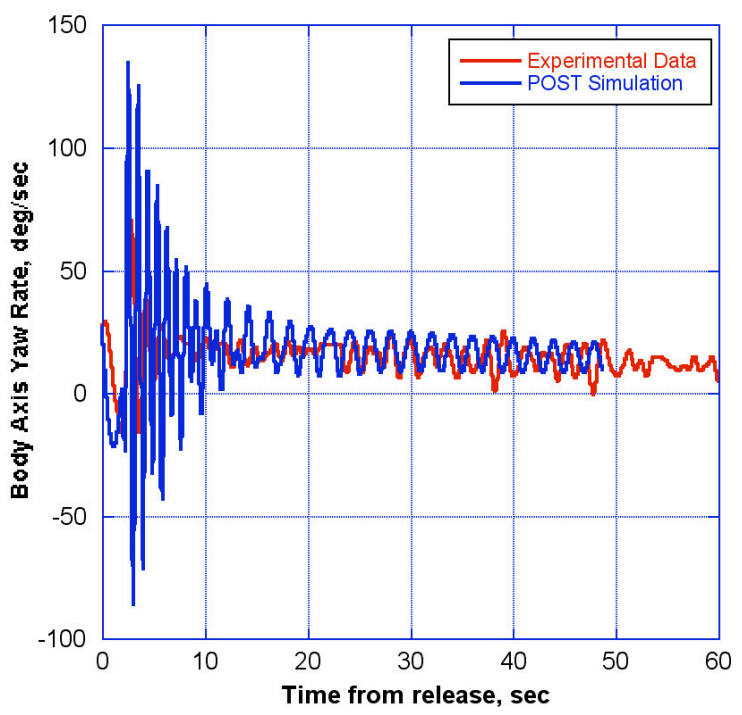

Figure 18. Effect of riser twist on simulation results. Alternate attachment points and modified damping. 
With this modification to the physical geometry of the model the predicted dynamic characteristics of the simulation are in much better agreement with the experimental data (Figure 18). The early part of the simulation still shows considerable differences but this is not unexpected given that in the experiment the risers are initially free of twist and the simulation models the risers with a fixed twist. It is unknown whether the full-scale system would exhibit this twisting behavior or not if the alternate attachment locations were used.

Figure 19 shows the impact of moving the drogue attachment points to the alternate location for the original nominal descent simulation for an initial roll rate of $40 \mathrm{deg} / \mathrm{sec}$. As mentioned earlier, this extreme attenuation of roll rate was the primary reason the alternated attachment locations were investigated. Using the modified damping and, where appropriate, the modified riser geometry the nominal descent simulation was used to reassess roll rate attenuation for both the nominal and alternate attachment points. For each configuration a range of roll rates was used in the initial conditions of the simulation. Figure 20 shows the comparison between the nominal and alternate attachment points for an initial roll rate of $40 \mathrm{deg} / \mathrm{s}$ (these results were typical for all initial roll rates investigated). It is clearly seen that with the simulation modified to reflect the physical understanding gained from the experiments that the alternate attachment location provides no benefit in terms of roll rate attenuation.

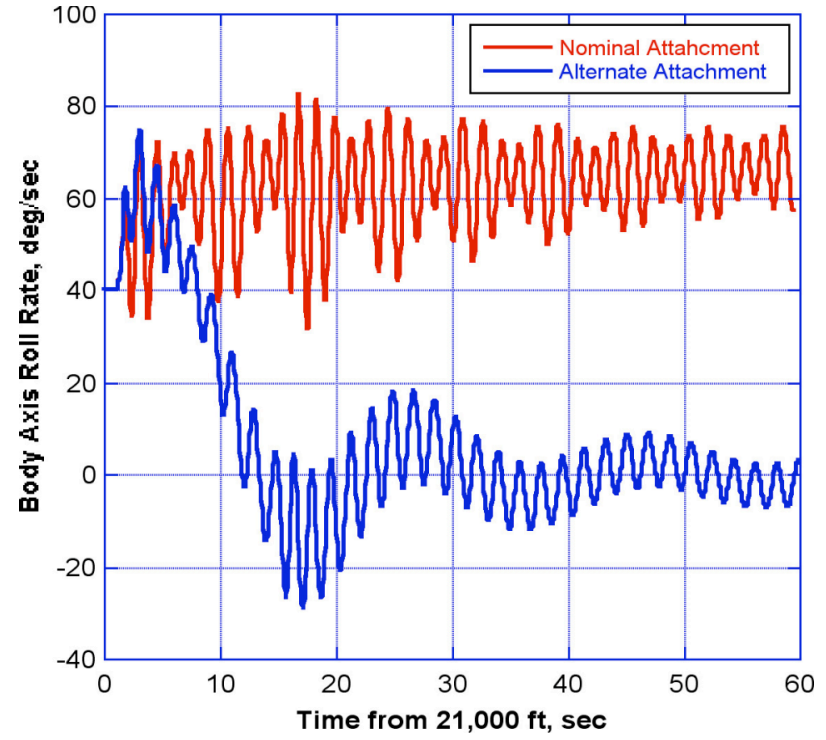

Figure 19. Effect of alternate attachment points on roll rate using the original simulation.

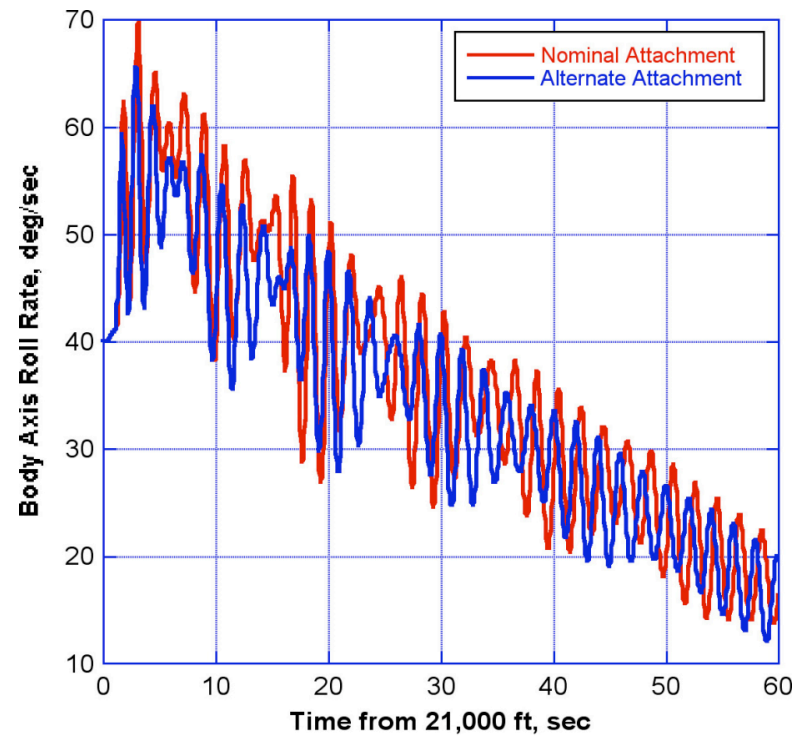

Figure 20. Effect of alternate attachment points using the modified simulation.

\section{Conclusions}

A wind tunnel test of the NASA Orion Crew Module (CM) with drogue parachutes was carried out in the 20Foot Vertical Spin Tunnel located at the NASA Langley Research Center (NASA/LaRC) in Hampton, Virginia. The model was a $1 / 29$-scale $(3.45 \%)$ representation of the vehicle geometry. The primary objective of this work was to assess the ability of the Orion Crew Module drogue parachute system to adequately stabilize the CM and reduce angular rates prior to main parachute deployment at low subsonic Mach numbers. The model was dynamically scaled to properly represent the mass and moments of inertia of the vehicle operating at an altitude of 25000 feet. The Reynolds number during the tests was approximately 225,000 based on model maximum diameter, and the Mach number was 0.05 .

Conclusions can be divided into three categories: VST test results, experimental data and simulation comparison, and nominal descent simulation results. The VST results indicated that the alternate attachment point did show a somewhat greater tendency to attenuate initial roll rate and reduce roll rate oscillations than the nominal attachment point. And while pitch rate oscillations were not affected, the magnitude of yaw rate oscillations was reduced when using the alternated attachment points. The magnitude of the pitch and yaw rate oscillations were also insensitive to the initial roll rate. 
The comparison of the experimental data to the POST II simulation of the experiment yielded some interesting observations on the aerodynamic database and the modeling of the parachute system. Comparison of results for the nominal attachment point seem to indicate that the low-speed pitch and yaw damping derivatives in the aerodynamic database are not in agreement with damping characteristics inferred from the experiments. While the modified damping derivatives did improve both the roll rate attenuation comparison and the pitch/yaw rate oscillation comparison it needs to be restated that there is little but engineering judgment behind these modified values and further analysis is needed to attempt to extract more realistic values. The primary driver in the roll rate attenuation mechanism appears to be the yaw damping derivative. And lastly for the experiment/simulation comparison, riser twist plays a significant role in determining the roll rate response for the alternate attachment points. Using a simple approximation of the riser twist resulted in a reduced roll rate attenuation that better compared with the experimental results.

Finally, using the modified POST II simulation to reevaluate the impact of the alternate attachment points showed significantly reduced roll rate attenuation tendencies when compared to the original simulation. Based on these results using the modified damping and accounting for riser twist, the alternate attachment point does not appear to offer a significant increase in allowable roll rate over the nominal configuration.

\section{Acknowledgments}

\section{References}

${ }^{2} 1$ U.S. Standard Atmosphere, 1976, U.S. Government Printing Office, Washington, D.C., 1976.

${ }^{2}$ Wolowicz, Chester, H.; Bowman, James, S.; and Gilbert, William, P.: Similitude Requirements and Scaling Relationships as Applied to Model Testing. NASA TP-1435, August 1979.

${ }^{3}$ Raiszadeh, Ben; and Queen, Eric M.: Partial Validation of Multibody Program to Optimize Simulated Trajectories II (POST II) Parachute Simulation with Interacting Forces. NASA TM-2002-211634, April 2002.

${ }^{4}$ Knacke, Theo W.: Parachute Recovery System Design Manual, Para Publishing, 1992, pp 5-42 to 5-45.

${ }^{5}$ Boisseau, Peter C.: Low-Speed Static and Oscillatory Stability Characteristics of a Model of the Apollo Launch-Escape Vehicle and Command Module. NASA TM X-894. October 1963. 